\title{
An Analysis of Eruption of the Sun Detected by Solar Radio Burst Type I
}

\author{
Z. S. Hamidi ${ }^{1 *}$, N. N. M. Shariff ${ }^{2}$, S. Arifin ${ }^{1}$, C. Monstein ${ }^{3}$ \\ ${ }^{1}$ School of Physics and Material Sciences, Faculty of Sciences, MARA University of Technology, \\ 40450, Shah Alam, Selangor, Malaysia \\ ${ }^{2}$ Academy of Contemporary Islamic Studies (ACIS), MARA University of Technology, 40450, Shah \\ Alam, Selangor, Malaysia \\ ${ }^{3}$ Institute of Astronomy, Wolfgang-Pauli-Strasse 27, Building HIT, Floor J, CH-8093 Zurich, \\ Switzerland \\ *E-mail address: zetysh@salam.uitm.edu.my
}

\begin{abstract}
Type I solar burst were identified based on data recorded by CALLISTO BLEIN, Switzerland in the period of $17^{\text {th }}$ of January, 2011. Solar Radio Burst Type I is one of the main type of solar burst which is believed to provide a diagnostic of electron acceleration in the corona. This noise storm burst is associated with emerging and growing active regions and last from hours to days. It can be observed that solar radio burst type I is formed within four minutes, although the number of sunspots is just 15. The results of the recent time indicate that Sunspot group 1147 has been mostly quiet since it rounded the eastern limb, but previous week's far side activity shows it is capable of significant eruptions. In 2011, only one day has been detected with spotless day, which means that it is about 7\% of overall cases. Probabilities for significant disturbances in Earth's magnetic field are given for three activity levels: active, minor storm, severe storm. From the current conditions in the space weather website on 16th January 2011 that is the first event was shown that the solar wind occurred with a speed of $433.2 \mathrm{~km} / \mathrm{second}$ while its density about 3.2 protons $/ \mathrm{cm} 3$. Besides the solar wind, X-ray solar flare with 6 hours maximum: B1 at 1846 UT and 24 hours: B2 at 1544 UT were detected. While type I seem to be an indicator of pre-solar flare and CMEs, on the observational analysis, we could not directly confirmed that this is the only possibility, and we need to consider other processes to explain in detailed the injection, energy loss and the mechanism of the acceleration of the particles. . We could conclude one active region will not produce a huge explosion of solar phenomena.
\end{abstract}

Keywords: Sun; low frequency; solar radio; burst; type I; e-CALLISTO

\section{INTRODUCTION}

Solar Radio Burst Type I is one of the main type of solar burst which is believed to provide a diagnostic of electron acceleration in the corona. It appears in chains of five or more individual bursts. It is form as a storm radiation, which last for periods of hours or days and is the most common kind of solar radio emission at meter wavelengths. This burst consists of numerous narrow-band peaks, short duration, circularly polarized burst superimposed on a background of continuum radiation known as storms [1]. Normally, a continuum and bursts come together, but have varying flux ratios. This noise storm burst is associated with 
emerging and growing active regions and last from hours to days [2]. During solar maximum, the percentage of noise storm can exceed up to $13 \%$ and has been observed at $125 \mathrm{MHz}$. The burst often appears singly in time-frequency space. Irregularly, they tend to cluster together in tens or hundreds to form narrow-band "chains" of type I burst; the chain generally drifts slowly in frequency.

Type 1 radio noise storm head the list of solar events discovered at metric wavelength. Krucker [3]. The powerful noise storms at a long time and it appear as intense, narrow band bursts, superposed on a low intensity broadband continuum, in the range of 30-400 MHz. The radiation of the noise storm's components has a very high degree of ordinary-mode circular polarization $(\sim 100 \%)$ and to be generated by the plasma emission mechanism. Plasma emission is any indirect emission process in which is the exciting agency generates plasma turbulence which cannot escape directly from the plasma, and this turbulence leads to escaping radiation through some secondary process [4]. Plasma emission occurs in solar radio bursts, of which there are several types with the most familiar being type III bursts due to beams of fast electrons[5].

The study conducted by Barta and Karlicky (2001) presents the observational results on this rapidly changing time and the frequency component of the metric Type I noise storm radiation, along the lines of their dynamic spectral characteristics and the implied plasma emission mechanism [6].This burst is very significant because it is an indicator of solar activities such as solar flare phenomenon [7]. Meanwhile, a flare is defined as a sudden, rapid, and intense variation in brightness. A solar flare occurs when the magnetic energy that has built up in the solar atmosphere is suddenly released [8]. The first solar flare was recorded in the observing sunspots at the time, when they viewed a large flare in white light. The radiation is emitted across virtually the entire electromagnetic spectrum, from radio waves at the long wavelength end, through optical emission to the X-rays and gamma rays at the short wavelength end. It should be noted that the amount of energy released is the equivalent of millions of 100-Megaton hydrogen bombs exploding at the same time [9].

The main objectives of this experiment are to identify the solar eruption evolution due to solar radio burst Type 1. The study of these features may provide new clues about the physical nature of the storm activity based on 2014 event. They assume an intermediate position between the phenomena related to the more gradual development of active regions, manifested in S-component and the short radio burst associated with flare [10].

\section{EXPERIMENTAL SETUP AND OBSERVATION}

We applied the background-subtractor tool to all recorded spectra [11]. Radio telescopes with antenna systems allow determination of the direction of the source of the solar burst radiation. The main detector, Compound Astronomical Low-frequency, Low-cost Instrument for Spectroscopy Transportable Observatories (CALLIISTO) system is used in obtaining a dynamic spectrum of solar radio burst data $[12,13]$. At our site, we have constructed the Log Periodic Dipole Antenna (LPDA) and this system was mounted on the top of the rooftop of National Space Centre (ANGKASA) building at Sg. Lang, Banting, Selangor located at (N $\left.02^{\circ} 49.488^{\prime} \mathrm{E} 101^{\circ} 36.168^{\prime}\right)$. This antenna covered from $45-870 \mathrm{MHz}[14,15]$. This antenna is connected to the spectrometer via cable RG 58 and the modification, calibration process and basic testing of the antenna has been done in order to improve the quality of the system $[16,17,18,19,20]$. Though, to avoid the interference signal, we focused the range of $150 \mathrm{MHz}$ till $350 \mathrm{MHz}[21,22]$. 


\section{RESULTS AND ANALYSIS}

Based on the observation, a fast drift Type I solar burst is formed intermittently within six hours period of observation starting from 09:43 UT TO 9:44 UT.

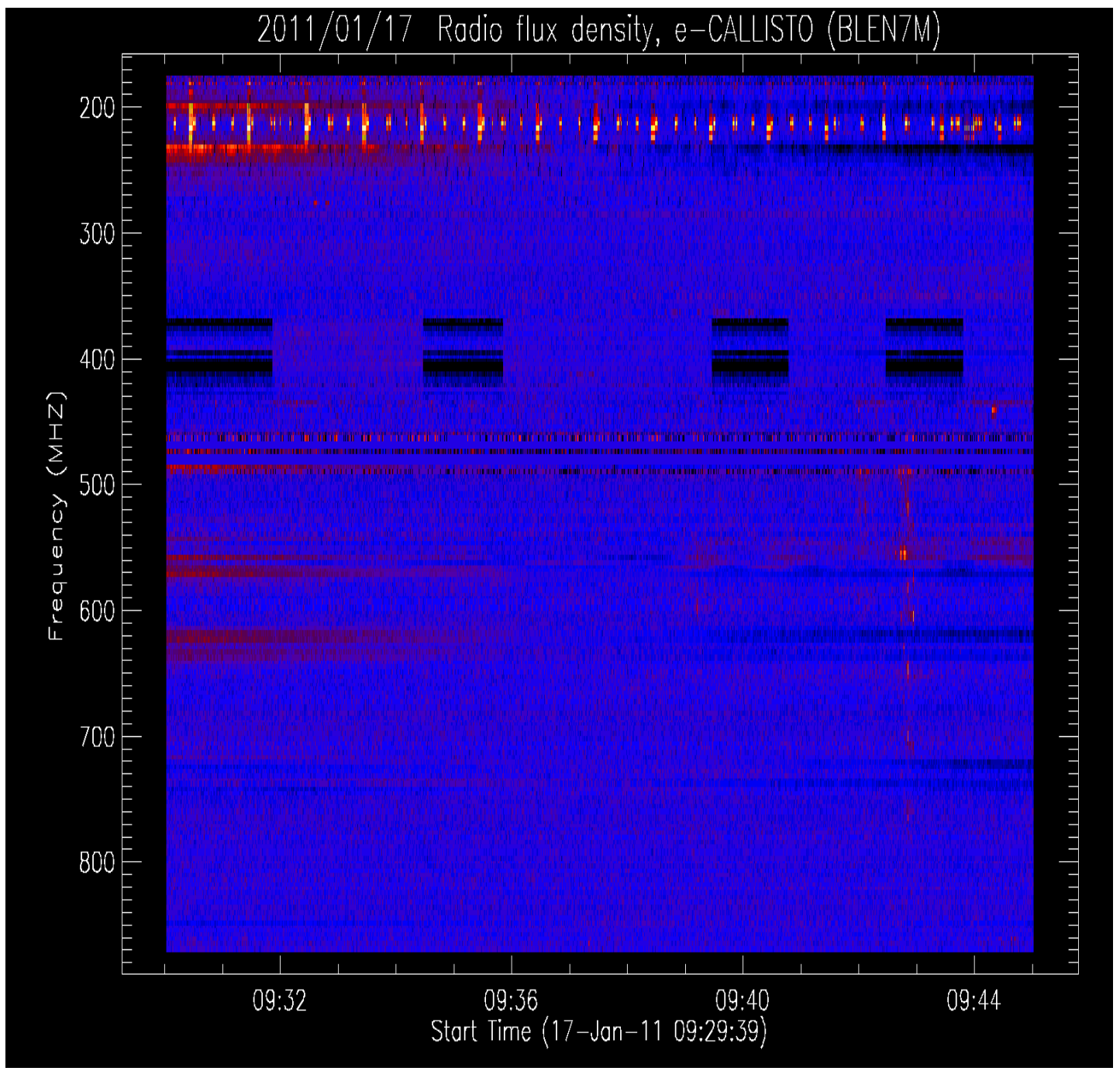

Figure 1. Burst Detection for the Event Solar Radio Burst Type I from 09:30 - 09:45 UT. 




Figure 2. Only one active region AR1147 could be observed on $17^{\text {th }}$ January 2011.

Figure 2 shows the active sunspot at 2200 UTC was shown that the M and X class flare with $1 \%$ of flare within 0 to 24 hours and followed by 24 to 48 hours. Probabilities for significant disturbances in Earth's magnetic field are given for three activity levels: active, minor storm, severe storm. From the current conditions in the space weather website on $16^{\text {th }}$ January 2011 that is the first event was shown that the solar wind occurred with a speed of $433.2 \mathrm{~km} / \mathrm{second}$ while its density about 3.2 protons $/ \mathrm{cm}^{3}$. Besides the solar wind, X-ray solar flare with 6 hours maximum: B1 at 1846 UT and 24 hours: B2 at 1544 UT were detected. Table 1-3 listed the potential of solar flare and geomagnetic storm at different altitudes.

Table 1. The potential of solar flare class M and X within 24 and 48 hours.

\begin{tabular}{|c|c|c|}
\hline FLARE & $0-24 \mathrm{hr}$ & $24-48 \mathrm{hr}$ \\
\hline CLASS M & $01 \%$ & $01 \%$ \\
\hline CLASS X & $01 \%$ & $01 \%$ \\
\hline
\end{tabular}

Table 2. The potential of geomagnetic storm at mid latitudes within 24 and 48 hours.

\begin{tabular}{|c|c|c|}
\hline & $0-24$ hour & $24-48$ hour \\
\hline ACTIVE & $05 \%$ & $15 \%$ \\
\hline MINOR & $01 \%$ & $01 \%$ \\
\hline SEVERE & $01 \%$ & $01 \%$ \\
\hline
\end{tabular}


Table 3. The potential of geomagnetic storm at high latitudes within 24 and 48 hours.

\begin{tabular}{|c|c|c|}
\hline & $0-24$ hour & $24-48$ hour \\
\hline ACTIVE & $10 \%$ & $20 \%$ \\
\hline MINOR & $01 \%$ & $01 \%$ \\
\hline SEVERE & $01 \%$ & $01 \%$ \\
\hline
\end{tabular}

The geomagnetic storms show the probabilities for significant disturbances in Earth's magnetic field were given for three activity levels, such as active, minor and severe storm. At the mid-latitudes, the active storm was shown that from 0 to 24 hours is about $5 \%$ of storm while from 24 to 48 hours the storms was increased to $15 \%$. The minor and severe shows that the same percentage of $1 \%$ of storm happened at that time. At the high latitude, active storm was recorded the highest percentage happen within 0 to 24 hours and 24 to 48 hours with $10 \%$ and $20 \%$ respectively. The minor and severe storm shows the same percentage of storm with $1 \%$ in 0 to 24 hours and 24 to 48 hours.

It can be observed that solar radio burst type I is formed within four minutes, although the number of sunspots is just 15. The results of the recent time indicate that Sunspot group 1147 has been mostly quiet since it rounded the eastern limb yesterday, but previous week's far side activity shows it is capable of significant eruptions. In 2011, only one day has been detected with spotless day, which means that it is about $7 \%$ of overall cases.

Table 4. The current condition of the Sun (Credited to Space Weather).

\begin{tabular}{|c|c|}
\hline Parameter & Value \\
\hline Solar wind speed & $433.2 \mathrm{~km} / \mathrm{second}$ \\
\hline Density & 1.5 protons $/ \mathrm{cm}^{3}$ \\
\hline Sunspot number & 15 \\
\hline $10.7 \mathrm{~cm}$ flux & $80 \mathrm{SFU}$ \\
\hline $6-\mathrm{hr}$ max & $\mathrm{B} 5$ \\
\hline $24-\mathrm{hr}$ & $\mathrm{B} 5$ \\
\hline
\end{tabular}

Table 4. displays the detailed parameter of each active region that can be observed directly from ground and space observation during $17^{\text {th }}$ January 2011 . There only one active region and the location of the active region can be found in the North region of the Sun. The Sun tends to be quiet with single storm, but not huge flare explosion is expected.

\section{CONCLUDING REMARKS}

While type I seem to be an indicator of pre-solar flare and CMEs, on the observational analysis, we could not directly confirmed that this is the only possibility, and we need to 
consider other processes to explain in detailed the injection, energy loss and the mechanism of the acceleration of the particles. More results of this type of burst should analyze to investigate the tendencies of possibility a huge solar flare and CMEs can be occur due to the eruption of the active region. We could conclude one active region will not produce a huge explosion of solar phenomena.

\section{Acknowledgement}

We are grateful to CALLISTO network, STEREO, LASCO,SDO/AIA, NOAA and SWPC make their data available online. This work was partially supported by the 600-RMI/FRGS 5/3 (135/2014) and 600RMI/RAGS 5/3 (121/2014) UiTM grants and Kemenetrian Pengajian Tinggi Malaysia. Special thanks to the National Space Agency and the National Space Centre for giving us a site to set up this project and support this project. Solar burst monitoring is a project of cooperation between the Institute of Astronomy, ETH Zurich, and FHNW Windisch, Switzerland, MARA University of Technology and University of Malaya. This paper also used NOAA Space Weather Prediction Centre (SWPC) for the sunspot, radio flux and solar flare data for comparison purpose. The research has made use of the National Space Centre Facility and a part of an initiative of the International Space Weather Initiative (ISWI) program.

\section{Biography}

Dr Zety Sharizat Hamidi is currently a lecturer and focused in Solar Astrophysics research specifically in radio astrophysics at the School of Physics and Material Sciences, Faculty of Sciences, MARA University of Technology, 40450, Shah Alam, Selangor, Malaysia. Involve a project under the International Space Weather Initiative (ISWI) and also a lecturer in School of Physics and Material Science, at MARA University of Technology, Shah Alam Selangor.

Syahirah Arifin is an undergraduate student at the School of Physics and Material Sciences, Faculty of Sciences, MARA University of Technology, 40450, Shah Alam, Selangor, Malaysia.

C.Monstein is a senior Engineer at Institute of Astronomy, Wolfgang-Pauli-Strasse 27, Building HIT, Floor J, CH-8093 Zurich, Switzerland and one of the researchers who initiated the CALLISTO system around the world.

Dr Nur Nafhatun Md Shariff is a senior lecturer in Academy of Contemporary Islamic Studies (ACIS), MARA University of Technology, 40450, Shah Alam, Selangor, Malaysia.Her current research is more on sustainability; environmental aspect. She is looking forward for cross-field research, i.e. solar astrophysics, light pollution measurement (mapping) and religious studies.

\section{References}

[1] K. Kai, Melrose, D., Suzuki, S., Storms (1985) 415.

[2] J.M. Maville, Astron. J. 135 (1962).

[3] S. Krucker, R.P. Lin, Two classes of solar proton events derived from onset time analysis, Astrophys. J. 542 (2000) 61-64.

[4] D.B. Melrose, Plasma emission due to isotropic fast electrons, and types I, II, and V solar radio bursts, Sol. Phys. 43 (1975) $211-236$.

[5] G. Mann, Coronal Magnetic Energy Releases, Springer, Berlin, 1995.

[6] M. Karlický, Bárta, J.i.k. M., K., H. Mészárosová, H.S. Sawant, F.C.R. Fernandes, J.R. Cecatto, A\&A 375 (2001). 
[7] A. Kruger, Introduction to Solar Radio Astronomy and Radio Physics, D. Reidel, Publ. Co., Dordrecht, Holland, 1979.

[8] B. Kliem, M. Karlick'y, A.O. Benz, Solar flare radio pulsations as a signature of dynamic magnetic reconnection, Astron. Astrophys. 360 (2000) 715-728.

[9] N. Gopalswamy, Radio-rich Solar Eruptive Events, Geophys. Res. Lett 27 (2000).

[10] Z.S.Hamidi, U.F.S.U. Ibrahim, Z.Z. Abidin, Z.A. Ibrahim, N.N.M.Shariff, Theoretical Review of Solar Radio Burst III (SRBT III) Associated With of Solar Flare Phenomena, International Journal of Fundamental Physical Sciences 3 (2013) 20-23.

[11] Z. Hamidi, N. Shariff, C. Monstein, First Light Detection of A Single Solar Radio Burst Type III Due To Solar Flare Event, (2014).

[12] N. Anim, Z. Hamidi, Z. Abidin, C. Monstein, N. Rohizat, Radio frequency interference affecting type III solar burst observations, 2012 NATIONAL PHYSICS CONFERENCE:(PERFIK 2012), American Institute of Physics, 2013, pp. 82-86.

[13] Z.S. Hamidi, Probability of Solar Flares Turn Out to Form a Coronal Mass Ejections Events Due to the Characterization of Solar Radio Burst Type II and III, Scientific Publishing, 2014, pp. 85.

[14] Z.S. Hamidi, Z. Ibrahim, Z. Abidin, M. Maulud, N. Radzin, N. Hamzan, N. Anim, N. Shariff, Designing and Constructing Log Periodic Dipole Antenna to Monitor Solar Radio Burst: e-Callisto Space Weather, International Journal of Applied Physics and Mathematics 2 (2011) 3.

[15] Roslan Umar, Zamri Zainal Abidin, Zainol Abidin Ibrahim, Mohd Saiful Rizal Hassan, Zulfazli Rosli, Z.S.Hamidi, Population density effect on radio frequencies interference (RFI) in radio astronomy, ICPAP 2012, AIP Conference Proceedings, Bandung Indonesia, 2012, pp. 4.

[16] Z.S.Hamidi, S. Chumiran, A. Mohamad, N. Shariff, Z. Ibrahim, N. Radzin, N. Hamzan, N. Anim, A. Alias, Effective temperature of the sun based on log periodic dipole antenna performance in the range from $45 \mathrm{Mhz}$ to $870 \mathrm{Mhz}$, American Journal of Modern Physics 2 (2013) 4.

[17] Z.S.Hamidi, Z. Abidin, Z. Ibrahim, N. Shariff, C. Monstein, Modification and Performance of Log Periodic Dipole Antenna, International Journal of Engineering Research and Development 3 (2012) 36-39.

[18] Z.S.Hamidi, Z. Abidin, Z. Ibrahim, C. Monstein, N. Shariff, Signal Detection Performed by Log Periodic Dipole Antenna (LPDA) in Solar Monitoring, International Journal of Fundamental Physical Sciences 2 (2012) 32-34.

[19] Z.S.Hamidi, N.M.Anim, N. N.S.Hakimi, N.Hamzan, A.Mokhtar, N.Syukri, S.Rohizat, I.Sukma, Z.A. Ibrahim, Z.Z.Abidin, N.N.M.Shariff, C.Monstein, Application of Log Periodic Dipole Antenna (LPDA) in Monitoring Solar Burst at Low Region Frequencies Region International Journal of Fundamental Physical Sciences 2 (2012) 4.

[20] Z.S.Hamidi, N.N.M. Shariff, Determination of Isotropic Source Spectral Power of the Log Periodic Dipole Antenna (LPDA), International Journal of Science and Mathematics 2 (2014) 3. 
[21] Z.S.Hamidi, Z. Abidin, Z. Ibrahim, N. Shariff, Indication of radio frequency interference (RFI) sources for solar burst monitoring in Malaysia, ICPAP 2011, AIP Publisher, Indonesia, 2012, pp. 6.

[22] Z.S. Hamidi, N.N.M. Shariff, C. Monstein, High Time Resolution Observation of Solar Radio of A Group Type III And U Burst Associated of Solar Flares Event, The International Journal of Engineering 1 (2012) 3. 